\title{
Real-life outcomes in patients with neovascular age-related macular degeneration switched from ranibizumab to aflibercept
}

\author{
Akin Cakir*, Burak Erden, Selim Bolukbasi, Serkan Erdenoz, Ali Cihat Aslan and Mustafa Elcioglu \\ Okmeydani Training and Research Hospital, Eye Clinic, Istanbul
}

\begin{abstract}
Background: To report the short term real-life outcomes of neovascular age-related macular degeneration (nAMD) patients switched to intravitreal aflibercept after failure to prior ranibizumab treatment.

Methods: Thirty eyes of thirty refractory nAMD patients with previously treated with intravitreal ranibizumab, that switched to intravitreal aflibercept injections were enrolled. The best corrected visual acuity (BCVA) measurements and spectral domain optical coherence tomography (SD OCT) characteristics over time were evaluated.

Results: The mean age of the patients was $73.76 \pm 6.75$ years (range $58-88$ years). The mean central macular thickness $(\mathrm{CMT})$ decreased from $319.7 \pm 85.2 \mu \mathrm{m}$ at baseline to $261.7 \pm 74.3 \mu \mathrm{m}$ at 12 th week. This reduction was found to be statistically significant $(\mathrm{p}<0.001)$. After 12 weeks treatment period, the number of patients that presented with intraretinal fluid (IRF) decreased from 19 (63.3\%) to 10 (33.3\%). This improvement was found to be statistically significant ( $\mathrm{p}<0.001)$. By the same treatment period 24 patients $(80 \%)$ with high reflective foci $(\mathrm{HRF})$ was reduced to 12 patients $(40 \%)$ ( $\mathrm{p}<0.001)$. The mean $\mathrm{BCVA}$ improved from $1.0 \pm 0.75$ $\log$ MAR at baseline to $0.91 \pm 0.75$; however this change was not statistically signficant (p:0.097).
\end{abstract}

Conclusion: Switching to aflibercept resulted in a better anatomic response and visual stabilization in patients with nAMD resistant to ranibizumab treatment.

\begin{abstract}
Abbreviations: nAMD: The neovascular form of age-related macular degeneration, OCT: optical coherence tomography, CNV: choroidal neovascularization, VEGF: vascular endothelial growth factor, PGF: placental growth factor, SRF: subretinal fluid, IRF: intraretinal fluid, PED: pigment epithelial detachment, CMT: central macular thickness, HRF: hyper-reflective foci, BCVA: best corrected visual acuity.
\end{abstract}

\section{Introduction}

The neovascular form of age-related macular degeneration (nAMD), also known as wet AMD, is one of the major causes of visual loss in the elderly and is characterized by the development of choroidal neovascularization (CNV) [1,2]. The demonstration of vascular endothelial growth factor (VEGF)-A as the most important growth factor responsible for the pathophysiology of nAMD [3-5] led to the use of intravitreal anti VEGF therapy, that significantly improved the treatment outcome of these patients [6-10].

The ANCHOR and MARINA studies showed that monthly intravitreal injections of ranibizumab were efficient in the treatment of nAMD $[9,10]$. The efficacy was associated with the drug's ability to reduce hemorrhage, subretinal fluid and intraretinal edema. However, many patients need continuous treatment to protect disease stability, while others, regardless of continuous treatment, continuously suffer from persisiting disease activity that leads to visual loss [11-13]. The mechanism of this resistance is not known, but the possibility of tolerance or tachyphylaxis has been claimed in several studies $[11,12,14-17]$. Some eyes may have a better response, with resolution of fluid, with the switch to another anti-VEGF drug. Gasperini et al. [11] showed that $81 \%$ of their tachyphylactic patients responded positively after switching the intravitreal drug.

Aflibercept is a recombinant fusion protein that possesses the ability to bind all isoforms of VEGF-A, VEGF-B and placental growth factor (PGF) [18-20]. Various reports have claimed that aflibercept has a higher affinity to VEGF than both ranibizumab and bevacizumab [19-21]. The randomized trials VIEW 1 and VIEW 2 proved that aflibercept was noninferior to ranibizumab, with the advantage of a more reduced need for treatment, which decreases the risk associated with intravitreal injections [22]. And also, aflibercept may have theoretical pharmacological and clinical advantages in the treatment of non-responders when compared with bevacizumab and ranibizumab with its higher VEGF-binding affinity [13].

Several studies showed a significant improvement in visual and anatomical outcomes in eyes with persistent subfoveal fluid after switching to intravitreal aflibercept despite previous anti-VEGF treatment with ranibizumab or bevacizumab [23-27]. However, there are conflicting results. Kumar et al. [23] and Singh et al. [27]

Correspondence to: Akin Cakir, Okmeydani Training and Research Hospital, Eye Clinic, Istanbul, Tel: +905054984514; E-mail: dracakir@gmail.com.

Key words: Neovascular age-related macular degeneration, aflibercept, ranibizumab

Received: August 10, 2017; Accepted: September 18, 2017; Published: September 21, 2017 
showed a significant improvement in both visual and anatomical outcomes in switched eyes. Conversely, Homer et al. [24] did not report an improvement but a maintanance in macular thickness and visual acuity. Finally, Pinheiro-Costa et al. [26] demonstrated only an anatomical improvement in switched eyes.

The aim of this study was to evaluate visual and anatomical outcomes in patients who had insufficient response to ranibizumab and switched to intravitreal aflibercept.

\section{Materials and methods}

Thirty eyes of thirty consecutive nAMD patients with previously treated with intravitreal $0.5 \mathrm{mg}$ ranibizumab, that switched to a loading dose of 3 monthly intravitreal aflibercept injections due to the persisting disease activity were included to the study. The disease activity was defined as any persisting subretinal fluid (SRF), intraretinal fluid (IRF) and/or pigment epithelial detachment (PED) persisting after 3 consecutive intravitreal $0.5 \mathrm{mg}$ ranibizumab injection. The study was carried out in accordance with the tenets of the Declaration of Helsinki, and was approved by the institutional ethical committee.

The medical records of the patients were reviewed and the following parameters (before enrollment and after a loading phase of 3 consecutive monthly intravireal aflibercept injections) were all noted; demographic data, best corrected visual acuity (BCVA) measurements in $\operatorname{logMAR}$, the total number of ranibizumab injections (prior to enrollment), central macular thickness (CMT), presence of SRF, IRS, PED and hyper-reflective foci (HRF). PED and SRF height were also evaluated in the subgroup analysis.

Patients with a history of vitrectomy, prior treatment with verteporfin or subfoveal laser, uncontrolled glaucoma, or uveitis, and those with additional OCT pathologies that may influence the outcomes of the study such as epiretinal membrane and vitreomacular traction were excluded from the study. All the patients should have been followed up for at least 4 months after switching. The baseline (just before switching) and final (4 months after switching) measurements were analysed and the change in CMT and BCVA were calculated.

Cirrus HD-OCT (Carl Zeiss Meditec, Dublin, CA) were used to obtain the OCT scans. The OCT images of the patients were assessed by two experienced observer that masked to the patients' information and the average of both values was used for statistical analysis. SRF was defined as a nonreflective area between the neurosensory retina and the retinal pigment epithelium. SRF height was measured manually using digital calipers from posterior border of the neurosensory retina to the retinal pigment epithelium. The maximum height was accepted. IRF was defined as a diffuse nonreflective area within the neurosensory retina. PED was defined as an area of sharply demarcated, dome-shaped elevation of the retinal pigment epithelium. Maximum PED height was measured manually using digital calipers from Bruch's membrane to the base of the pigment epithelium. The presence of HRF was defined as scattered hyper-reflective spots into all retinal layers that was seen in at least one OCT scan.

SPSS software version 15.0 was used for statistical analyses. Descriptive analyses were presented using mean and standart deviation for continous variables, and percentages were used for categorical variables. Since the variables were not normally distributed, Friedman test was performed to assess whether there is a significant change in the variables over time. The Wilcoxon test was used to test the significance of pairwise differences using Bonferroni correction $(0.05 / 6=0.008)$ to adjust for multiple comparisons. While investigating the associations between non-normally distributed and/or categorical variables, the correlation coefficients and their significance were calculated using the Spearman test. The results were considered significant at $\mathrm{P}$ values $<0.05$.

\section{Results}

A total of 30 subjects were included in the study. The mean age of the patients was $73.76 \pm 6.75$ years (range $58-88$ years).Eighteen of the 30 eyes $(60 \%)$ were of male patients. Seventeen patients (54.8\%) were phakic. The average number of intravitreal ranibizumab injections prior to study entry was 9.1 (range 3-28 injections). The baseline intraocular pressure measured with Goldmann applanation tonometer was $15 \pm 3.02 \mathrm{mmHg}$ (range 10-21 $\mathrm{mmHg}$ ). At the end of the 12 -week follow-up, the mean IOP was $13.8 \pm 2.7 \mathrm{mmHg}$. None of the patients needed to be started an anti-glacomatous medication.

The mean BCVA improved from $1.0 \pm 0.75 \log$ MAR at baseline to $0.91 \pm 0.75$ at week 12 . Only 2 patients $(6.6 \%)$ lost one line visual acuity, 18 patients $(60 \%)$ were considered visually stable and 10 patients (33.4\%) gained at least one line visual acuity. The trend in BCVA was resembling to double-hump appearence. This change in BCVA over time was not statistically signficant (p:0.097)(Figure 1).

The mean CMT decreased from $319.7 \pm 85.2 \mu \mathrm{m}$ at baseline to 261.7 $\pm 74.3 \mu \mathrm{m}$ at week 12 . The trend in CMT was found to be statistically significant $(p<0.001)$. Post-hoc analyses showed that this significance was occured after the first injection and was limited to weeks 4 . There was no siginificant CMT change within the second and third intravitreal injection intervals, weeks 8-12 (Figure 2).

At baseline, the proportion of eyes with SRF was 56.7\% (17 patients) and this proportion decreased to $46.7 \%$ (14 patients) at week 24. Despite this improvement in SRF, it is not found to be statistically significant (p:0.112) (Figure 3). However, when we analyse just SRF height among patients with SRF, a statistically significant improvement is remarkable between baseline and week 4 (p:0.001, after bonferroni correction in post-hoc analysis) (Figure 4).

With regards to PEDs, $23.3 \%$ (7 patients) of the patients presented with PED at baseline, this proportion slightly decreased to $20 \%$ (6 patients) at week 12. This difference was not found to be statistically significant (p:0.392) (Figure 3). Nevertheless, when we look at PED height among patients with PED, a statistically significant improvement is remarkable between baseline and week 12 (p:0.008, after bonferroni correction in post-hoc analysis) (Figure 4).

Nineteen patients $(63,3 \%)$ presented with IRF at baseline and at week 12 only 10 patients (33.3\%) had still IRF. This improvement was found to be statistically significant $(\mathrm{p}<0.001)$. Post-hoc analyses showed that this improvement has emerged at week 8 (Figure 3).

A similar trend was found in HRF. Twenty-four patients (80\%) had HRF at baseline and this was reduced to 12 patients (40\%) at week 12 $(\mathrm{p}<0.001)$. Likewise, this improvement has occured at week 8 as in IRF (Figure 3).

Best corrected visual acuity (BCVA), Central macular thickness (CMT), Subretinal fluid (SRF), Pigment epithelial detachment (PED), Intraretinal fluid (IRF) and hyper-reflective foci (HRF) course over time. (Table 1).

In the correlation analyses, BCVA improvement was not associated with any parameters (such as number of ranibizumab injection prior to enrollment, baseline BCVA, baseline CMT, baseline presence of SRF,PED,IRF or HRF). However; CMT improvement was found to be 


\section{BCVA (logMAR)}

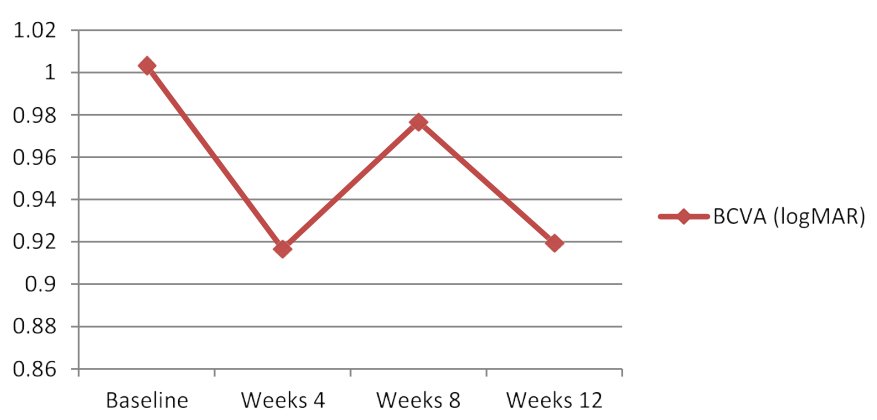

Figure 1. Best corrected visual acuity (BCVA) course over time.

\section{$\operatorname{CMT}(\mu)$}
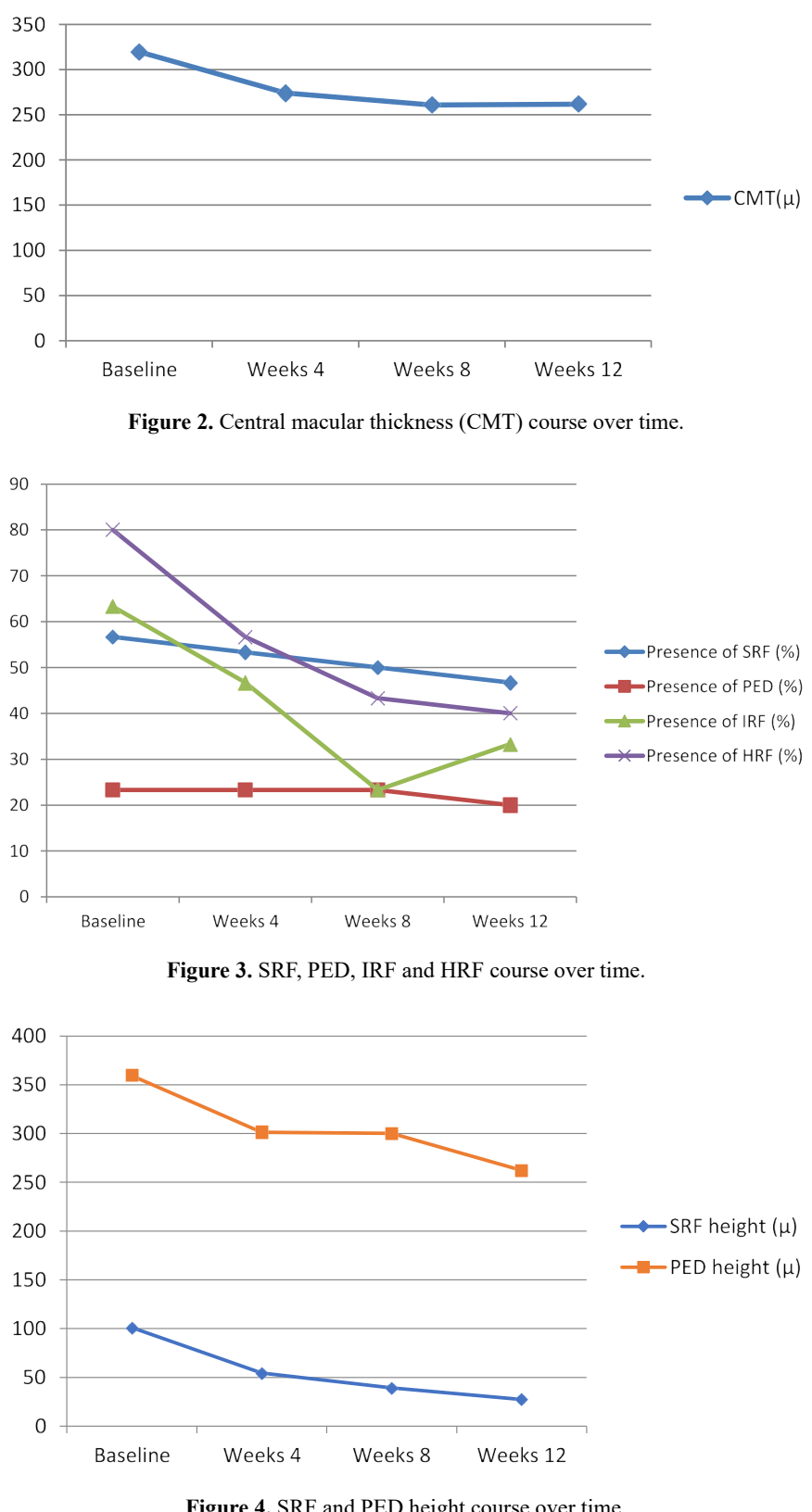

Figure 4. SRF and PED height course over time.
Table 1. Summarizes the changes in BCVA, CMT, presence of SRF, PED, IRF and HRF over time.

\begin{tabular}{|c|c|c|c|c|c|}
\hline & Baseline & Week 4 & Week 8 & Week 12 & P value \\
\hline $\begin{array}{c}\text { BCVA } \\
\text { (logMAR) }\end{array}$ & $1.00 \pm 0.75$ & $0.91 \pm 0.72$ & $0.97 \pm 0.75$ & $0.91 \pm 0.75$ & 0.097 \\
\hline CMT ( $\boldsymbol{\mu m})$ & $319.7 \pm 85.2$ & $274.0 \pm 87.6$ & $260.8 \pm 65.2$ & $261.7 \pm 74.3$ & $<\mathbf{0 . 0 0 1}$ \\
\hline $\begin{array}{c}\text { Presence of } \\
\text { SRF (\%) }\end{array}$ & $56.70 \%$ & $53.30 \%$ & $50 \%$ & $46.70 \%$ & 0.112 \\
\hline $\begin{array}{c}\text { Presence of } \\
\text { PED (\%) }\end{array}$ & $23.30 \%$ & $23.30 \%$ & $23.30 \%$ & $20 \%$ & 0.392 \\
\hline $\begin{array}{c}\text { Presence of } \\
\text { IRF (\%) }\end{array}$ & $63.30 \%$ & $46.70 \%$ & $23.30 \%$ & $33.30 \%$ & $<\mathbf{0 . 0 0 1}$ \\
\hline $\begin{array}{c}\text { Presence of } \\
\text { HRF (\%) }\end{array}$ & $80 \%$ & $56.70 \%$ & $43.30 \%$ & $40 \%$ & $<\mathbf{0 . 0 0 1}$ \\
\hline
\end{tabular}

statistically significant and moderately associated with baseline CMT (r: 0.501; p:0.005) and baseline SRF (r: -0.494; p:0.006) (Table 2).

\section{Discussion}

The current study presented the short term outcomes of the patients with refractory nAMD switched from intravitreal ranibizumab to aflibercept. Both visual and anatomical improvement was achieved in almost all the patients but only CMT, IRF and HRF improvement reached statistical significance. Subgroup analyses showed that SRF and PED height were also signficantly reduced.

We did not observe a significant improvement in BCVA. However, the vast majority of the patients maintained their initial BCVA. This may have resulted from our short follow-up time. Since Kumar et al. reported that a significant improvement in visual acuity was not observed after initial three injections but it was occured 6 months later [23]. On the other hand, Homer et al. did not declare a significant improvement in BCVA in their 24-month follow-up [24]. Most probably, BCVA improvement depends on multiple variables, such as initial IS/OS integrity, increasing age, increasing CMT, the presence of IRF and presence of PED [28]. Nevertheless, we did not establish such an association between BCVA improvement and any initial predictors in the Spearman correlation analysis. Besides, our small sample size did not enable us to perform a multiple logistic regression analysis.

We determined a significant reduction in CMT, particularly after the first injection. Most of the articles in the literature are in agreement with our results [23,26-28]. It seems that switching to aflibercept is more effective on CMT than BCVA improvement. Interestingly, initial CMT is found to be positively correlated with CMT reduction. The higher initial CMT decreases more, so it can not be accepted as a poor prognostic factor for CMT reduction.

The presence of SRF slightly decreased over time with no significance. However, SRF height reduced significantly after the first injection, furthermore, it was negatively correlated with CMT reduction emerging as a poor prognostic indicator. A similar trend was also observed in PED. While the presence of PED decreased insignificantly, PED height reduced significantly at the end of week 12. In a similar study by Major et al., a significant reduction in PED height in previously treated eyes with nAMD was reported [25]. We believe that continuos treatment with aflibercept after the first three injections may result in better outcomes for both parameters.

To best our knowledge, there were two studies in the literature that focused on IRF and HRF in the switching patients with refractory nAMD $[28,29]$. Both studies showed that the switch from ranibizumab to aflibercept led to a significant decrease in the number of HRF. In our study, we also noted an improvement in both IRF and HRF over time, 
Table 2. Spearman correlation analysis showed statistically significant and moderate correlation between CMT improvement and baseline CMT-SRF.

\begin{tabular}{|c|c|c|c|c|c|c|c|c|}
\hline & & $\begin{array}{c}\text { Number of } \\
\text { Ranibizumab } \\
\text { injection prior to } \\
\text { study entry }\end{array}$ & Baseline BCVA & Baseline CMT & Baseline SRF & Baseline PED & Baseline IRF & Baseline HRF \\
\hline \multirow{2}{*}{$\begin{array}{c}\text { BCVA } \\
\text { improvement }\end{array}$} & $\mathbf{R}$ & 0.145 & 0.187 & -0.132 & -0.108 & -0.147 & 0.037 & 0.245 \\
\hline & P value & 0.444 & 0.323 & 0.486 & 0.57 & 0.437 & 0.846 & 0.192 \\
\hline \multirow{2}{*}{$\begin{array}{c}\text { CMT } \\
\text { improvement }\end{array}$} & $\mathbf{R}$ & 0.286 & -0.005 & 0.501 & -0.494 & -0.15 & 0.288 & -0.149 \\
\hline & P value & 0.125 & 0.979 & 0.005 & 0.006 & 0.428 & 0.123 & 0.431 \\
\hline
\end{tabular}

particularly at weeks 8 . Moreover, eyes with IRF at baseline were found to be more responsive to intravitreal aflibercept than eyes with SRF. Since HRF is accepted to be a sign of acute inflammation, intravitreal aflibercept may have such an anti-inflammatory effect. Some reports in the literature supports this finding. Kanda et al. demonstrated that aflibercept has a neutralizing effect against galectin-1, an angiogenic factor associated with proliferative diabetic retinopathy [30].

Limitations of this study include small sample size, short followup time and retrospective design. However, most the studies in the literature suffer from this similar issues. A prospective randomized controlled trial with strict inclusion cirteria must be conducted.

The current study indicates that aflibercept can achieve better anatomic response in patients with nAMD resistant to ranibizumab treatment. In addition, stabilization of BCVA seems to be possible. This effect may be due to the higher affinity of aflibercept to VEGF-A with the additional ability to bind VEGF-B and PGF. Switching to aflibercept should be considered in refractory patients.

\section{References}

1. Bressler NM, Bressler SB, Congdon NG, Ferris FL 3rd, Friedman DS, et al. (2003) Potential public health impact of Age-Related Eye Disease Study results: AREDS report No 11. Arch Ophthalmol 121: 1621-1624. [Crossref]

2. Klein R, Peto T, Bird A, Vannewkirk MR (2004) The epidemiology of age-related macular degeneration. Am J Ophthalmol 137: 486-495. [Crossref]

3. Adamis AP, Shima DT (2005) The role of vascular endothelial growth factor in ocular health and disease. Retina 25: 111-118. [Crossref]

4. Carneiro AM, Costa R, Falcão MS, Barthelmes D, Mendonça LS, et al. (2012) Vascular endothelial growth factor plasma levels before and after treatment of neovascular agerelated macular degeneration with bevacizumab or ranibizumab. Acta Ophthalmol 90: e25-30. [Crossref]

5. Stewart MW (2012) Clinical and differential utility of VEGF inhibitors in wet age-related macular degeneration: focus on aflibercept. Clin Ophthalmol 6: 1175-1186. [Crossref]

6. Andreoli CM, Miller JW (2007) Anti-vascular endothelial growth factor therapy for ocular neovascular disease. Curr Opin Ophthalmol 18: 502-508. [Crossref]

7. Carneiro AM, Falcao MS, Brandao EM, Falcao-Reis FM (2010) Intravitreal bevacizumab for neovascular age-related macular degeneration with or without prior treatment with photodynamic therapy: one-year results. Retina 30: 85-92. [Crossref]

8. Meyer CH, Holz FG (2011) Preclinical aspects of anti-VEGF agents for the treatment of wet AMD: ranibizumab and bevacizumab. Eye (Lond) 25: 661-672. [Crossref]

9. Brown DM, Michels M, Kaiser PK, Heier JS, Sy JP, et al. (2009) Ranibizumab versus verteporfin photodynamic therapy for neovascular age-related macular degeneration: two-year results of the ANCHOR study. Ophthalmology 116: 57-65.e55.

10. Rosenfeld PJ, Brown DM, Heier JS, Boyer DS, Kaiser PK, et al. (2006) Ranibizumab for neovascular age-related macular degeneration. $N$ Engl J Med 355: 1419-1431. [Crossref]

11. Gasperini JL, Fawzi AA, Khondkaryan A, Lam L, Chong LP, et al. (2012) Bevacizumab and ranibizumab tachyphylaxis in the treatment of choroidal neovascularisation. $\mathrm{Br} J$ Ophthalmol 96: 14-20. [Crossref]

12. Keane PA, Liakopoulos S, Ongchin SC, Heussen FM, Msutta S, et al. (2008) Quantitative subanalysis of optical coherence tomography after treatment with ranibizumab for neovascular age-related macular degeneration. Invest Ophthalmol Vis Sci 49: 3115-3120. [Crossref]
13. Bakall B, Folk JC, Boldt HC, Sohn EH, Stone EM, et al. (2013) Aflibercept therapy for exudative age-related macular degeneration resistant to bevacizumab and ranibizumab. Am J Ophthalmol 156: 15-22. [Crossref]

14. Eghøj MS, Sørensen TL (2012) Tachyphylaxis during treatment of exudative agerelated macular degeneration with ranibizumab. Br J Ophthalmol 96: 21-23. [Crossref]

15. Schaal S, Kaplan HJ, Tezel TH (2008) Is there tachyphylaxis to intravitreal anti-vascular endothelial growth factor pharmacotherapy in agerelated macular degeneration? Ophthalmology 115: 2199-2205. [Crossref]

16. Binder S (2012) Loss of reactivity in intravitreal anti-VEGF therapy: tachyphylaxis or tolerance? BrJ Ophthalmol 96: 1-2. [Crossref]

17. Forooghian F, Cukras C, Meyerle CB, Chew EY, Wong WT (2009) Tachyphylaxis after intravitreal bevacizumab for exudative age-related macular degeneration. Retina 29 723-731. [crossref]

18. Stewart MW (2012) Aflibercept (VEGF Trap-eye): the newest anti-VEGF drug. $B r J$ Ophthalmol 96: 1157-1158. [Crossref]

19. Papadopoulos N, Martin J, Ruan Q, Rafique A, Rosconi MP, et al. (2012) Binding and neutralization of vascular endothelial growth factor (VEGF) and related ligands by VEGF Trap, ranibizumab and bevacizumab. Angiogenesis 15: 171-185. [Crossref]

20. Semeraro F, Morescalchi F, Duse S, Parmeggiani F, Gambicorti E, et al. (2013) Aflibercept in wet AMD: specific role and optimal use. Drug Des Devel Ther 7: 711722. [Crossref]

21. Stewart MW, Rosenfeld PJ (2008) Predicted biological activity of intravitreal VEGF Trap. Br J Ophthalmol 92: 667-668. [Crossref]

22. Heier JS, Brown DM, Chong V, Korobelnik JF, Kaiser PK, et al. (2012) Intravitreal aflibercept (VEGF Trap-eye) in wet age-related macular degeneration. Ophthalmology 119: 2537-2548. [Crossref]

23. Kumar N, Marsiglia M, Mrejen S, Fung AT, Slakter J, et al. (2013) Visual And Anatomical Outcomes Of Intravitreal Aflibercept In Eyes With Persistent Subfoveal Fluid Despite Previous Treatments With Ranibizumab In Patients With Neovascular Age-Related Macular Degeneration. Retina 33:1605-1612.[Crossref]

24. Homer N, Grewal DS, Mirza RG, Lyon AT, Gill MK. Transitioning to intravitreal aflibercept following a previous treat-and-extend dosing regimen in neovascular agerelated macular degeneration:24-month results. Eye 29:1152-1155. [Crossref]

25. Major JC, Wykoff CC, Croft DE, Wang R, Mariani AF, et al. (2015) Aflibercept for pigment epithelial detachment for previously treated neovascular age-related macular degeneration. Can J Ophthalmol 50: 373-377. [Crossref]

26. Pinheiro-Costa J, Costa JM, Beato JN, Freitas-da-Costa P, Brandão E, et al. (2015) Switch to Aflibercept in the Treatment of Neovascular AMD: One-Year Results in Clinical Practice. Ophthalmologica 233: 155-161. [Crossref]

27. Singh RP, Srivastava S, Ehlers JP, Bedi R, Schachat AP, et al. (2014) A single-arm, investigator-initiated study of the efficacy, safety and tolerability of intravitreal aflibercept injection in subjects with exudative age-related macular degeneration, previously treated with ranibizumab or bevacizumab: 6-month interim analysis. $\mathrm{Br} J$ Ophthalmol 98: i22-i27. [Crossref]

28. Chatziralli I, Nicholson L, Vrizidou E, Koutsiouki C, Menon D, et al. (2016) Predictors of Outcome in Patients with Neovascular Age-Related Macular Degeneration Switched from Ranibizumab to 8-Weekly Aflibercept. Ophthalmology 1e9. [Crossref]

29. Abri Aghdam K, Pielen A, Framme C, Junker B. (2015) Correlation between hyperreflective foci and clinical outcomes in neovascular age-related macular degeneration after switching to aflibercept. Invest Ophthalmol Vis Sci 56: 6448-55. [Crossref]

30. Kanda A, Noda K, Saito W, Ishida S (2015) Aflibercept Traps Galectin-1, an Angiogenic Factor Associated with Diabetic Retinopathy. Sci Rep 5: 17946. [Crossref]

Copyright: (C2017 Cakir A. This is an open-access article distributed under the terms of the Creative Commons Attribution License, which permits unrestricted use, distribution, and reproduction in any medium, provided the original author and source are credited. 